\title{
AIRPHOTO LINEAMENTS IN THE CALEDONIA AREA OF SOUTHERN NEW BRUNSWICK
}

\author{
WIN NAING \\ University, Rangoon, Burma \\ E.Z. LAJTAI \\ Department of Geology, University of New Brunswick, Fredericton, New Brunswick
}

\begin{abstract}
A system of photogeologic interpretation has been applied on a regional scale in the Caledonia area of New Brunswick, Canada. The orientation of about 700 photolineaments has been measured and their distribution analyzed. A statistical partitioning technique applied to the whole region produced six major trends with the strongest trends occurring at $097^{\circ} \pm 7^{\circ}, 265^{\circ} \pm 6^{\circ}$ and $242^{\circ} \pm 9^{\circ}$. None of the strong trends coincides with the orientation of major faults in the area. Detailed examination of stmuctural domains suggests the presence of more than six lineament trends. Correlation of trends from domain to domain is difficult and the genetic significance of lineaments in view of the scarcity of ground information, remains in doubt.
\end{abstract}

\section{INTRODUCTION}

In recent years considerable progress has been made by the New Brunswick Department of Natural Resources in mapping the geology of the Caledonia area of New Brunswick (Ruitenberg et al 1973, 1974, 1975). Simultaneously several geological and geophysical investigations have been conducted by faculty and students of the Department of Geology, University of New Brunswick (Tefirian 1974, Gupta 1975); also, a photogeologic study has just been completed by win Naing (1976). This paper is based on data produced by the latter study.

The study area, the Caledonian Highlands of New Brunswick (Howie and Cuming 1963), extends along the Bay of Fundy (Fig. 1) and involves a strip of ground approximately $24 \mathrm{~km}$ wide and $161 \mathrm{~km}$ long. Most of the area is located between Saint John, New Brunswick and Shepody Bay. The Highlands are a dissected mature peneplain (Greiner 1974) ranging in elevation between sea level and $380 \mathrm{~m}$. Upland areas are commonly formed by granitic rocks and massive $r$ yo tes. Low re $e$ an ro ng topograp y are typical characteristics of the less resistant sedimentary rocks. NOrtheast and north-northeast trends of rocks with ages from Precambrian to Triassic form prominent topographic trends. Major faults, recognizable as steep scarps extending in places more than $14 \mathrm{~km}$ follow the same general trend (Naing 1976).

The study area is part of the Kennebecasis Geanticline of Potter (1966) characterized by a thick succession of Late Precambrian volcanic and sedimentary rocks which are in places overlain by Cambrian and Ordovician shales and sandstones. In peripheral areas, there are outcroppings of Carboniferous and Triassic Rocks.

For the study of the distribution of photolineaments, the whole area has been divided into 10 domains with boundaries drawn along geological contacts. These are as follows (Fig. 2):

I The Tiassic Quaco Formation

II The Pennsylvanian McCoy Head Formation

III The Pennsylvanian Boss Point Formation
IV The Mississippian-Pennsylvanian Hopewell Group

V The Lower Mississippian Horton Group

VI The Carboniferous Mispec Group

VII The Cambrian-Ordovician Saint John Group

VIII The Central Intrusive Belt (age unknown)

IX The Precambrian Coldbrook Group

X The Precambrian Greenhead Group

The above listing is arranged in time sequence although the relative positions of the Central Intrusive Belt and the Mispec Group have not been securely established. The 10 major domains have been further subdivided into 45 subdomains. The subdividing has been based on either spatial separation or, for formations of large extent, the boundaries have been drawn along major faults.

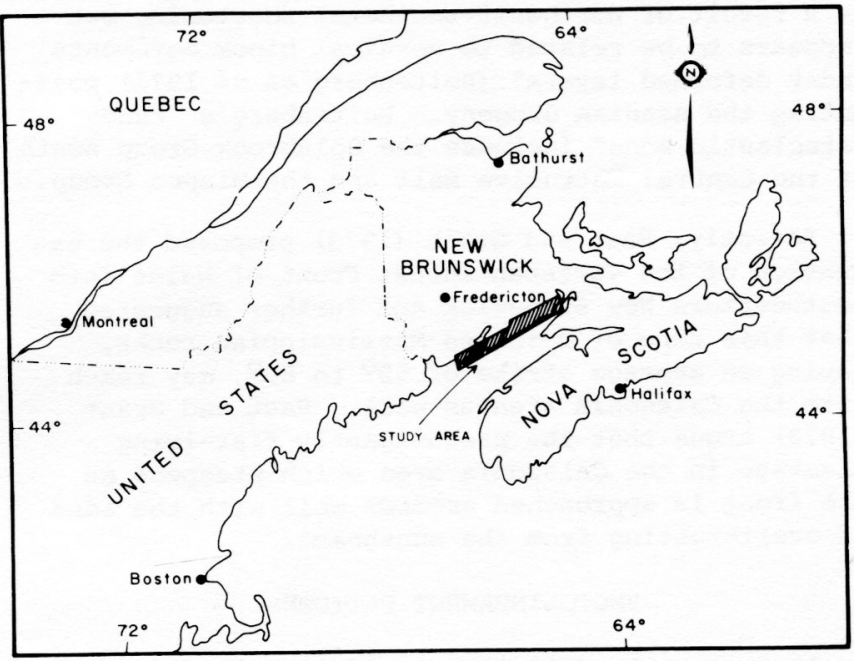

FIG. 1 Location map. 


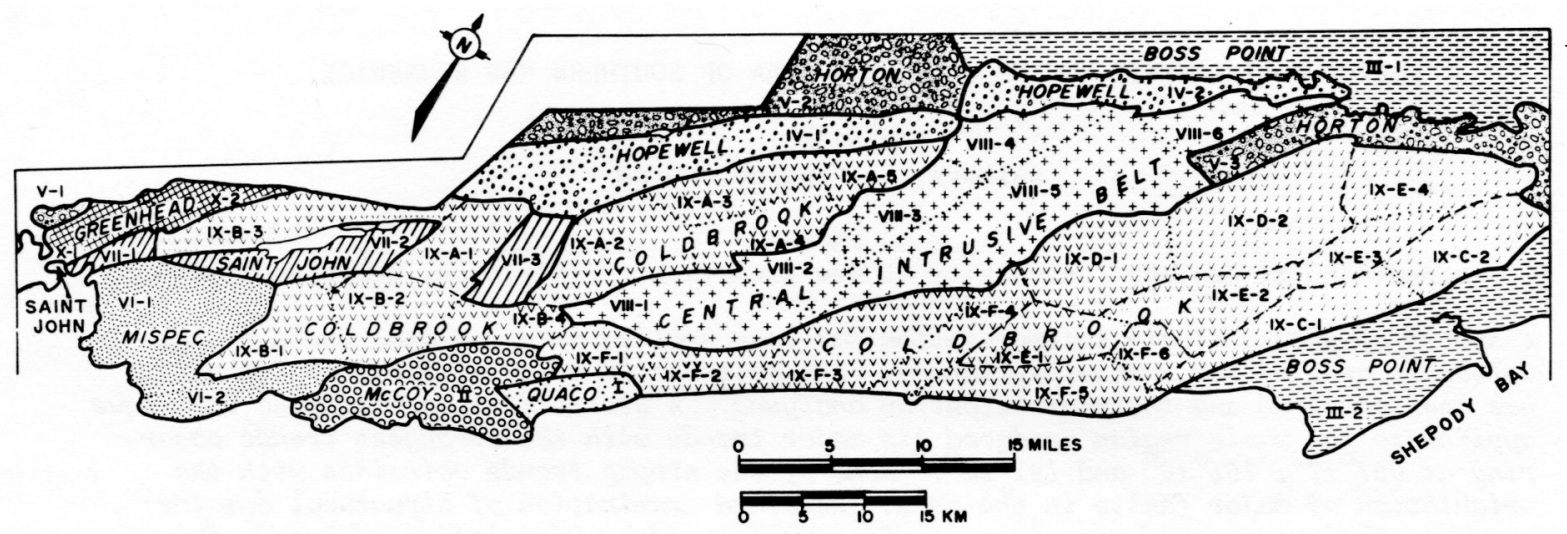

FIG. 2 Structural domains of the Caledonia area.

\section{STRUCTURAL GEOLOGY}

In the Caledonia area all rocks from Precambrian to Carboniferous display a characteristic northeasterly trend. This trend is also typical of the Canadian Appalachian region as a whole.

Ruitenberg et al (1973) divides the Caledonian Highlands into a northern and southern belt on based of structural style. The northern belt shows the typical style of the Acadian Orogeny, defined in Brown and Helmstaedt (1970) and Garnet and Brown (1973) as a deformed belt consisting of upright isoclinal folds with strong steep northeasterly axial planes and parallel first cleavage suggesting strong northwest-southeast shortening. Along the southern belt, the structural style is more complex. The first cleavage varies in dip from flat to steep and Ruitenberg et al (1973) argue that folding occurred by gravity sliding down the flanks of uplifted blocks. Thus the southern belt, "The Fundy Cataclastic zone" is suggested to have formed not as a result of northwest-southeast shortening but "appears to be related to vertical block movements under deformed layers" (Ruitenberg et al 1973) postdating the Acadian Orogeny. Ruitenberg's "Fundy Cataclastic Zone" includes the Coldbrook Group south of the Central Intrusive Belt and the Mispec Group.

Recently, Rast and Grant (1973) proposed the extension of the Variscan Thrust Front of wales into southwestern New Brunswick and further suggested that this zone of deformed Mississippian rocks, having an average strike of $55^{\circ}$ to $60^{\circ}$, may reach into the Caledonia area as well. Rast and Grant (1973) argue that the predominantly flat-lying cleavage in the Caledonia area which steepens as the front is approached accords well with the idea of overthrusting from the southeast.

\section{PHOTOLINEAMENT PATTERNS}

Approximately 7000 lineaments with an average length of about one mile have been detected on aerial photographs, roughly 150 in each of the 45 subdomains. Frequency diagrams showing the angular distribution of lineaments for each subdomain are shown in Figure 3. The conventional smoothing technique using the formula of (smoothed frequency = $f(n-l)+2 f(n)+f(n+2)\}$ has been applied to the raw data.
The complexity of patterns displayed by Figure 3 suggests the degree of difficulty involved in the interpretation of trends and the security of any conclusion drawn from such data. One may get anywhere between 6 and 12 lineament trends in the Caledonia area. For example, when all the lineaments are included, and a homogeneous polymodal distribution of trends is assumed with trends showing frequencies less than 5 percent omitted, a partitioning technique (Sinclair 1974) produces 6 trends (Fig. 4). The assumption of homogeneous populations from subdomain to subdomain is clearly preposterous (Fig. 5). For example, each formation of the Mispec Group displays a characteristic and clearly similar three-peak distribution, but the second peak varies by $20^{\circ}$ in azimuth. Knowing the curving nature of major faults in the area (Ruitenberg et al 1975), this should not come as a surprise.

Another difficulty lies in the interpretation of the strongest trend, the east-west trend. The statistical analysis arrives at a mean trend of $097^{\circ}$ with standard deviation at \pm 7 percent. A single $097^{\circ}$ trend is quite clearly indicated on Figure 3 for some of the younger formations (e.g. Quaco, McCoy). In others, especially in the Precambrian Coldbrook Group the strong east-west trend is rather diffuse and in many subdomains the existence of more than a single lineament trend is indicated. Similar problems of statistical techniques in favour of correlation based on simple inspection and comparison of the nature of the various frequency diagrams. Through this process, it was found that some subdomains are similar enough to be combined. For example, the 23 subdomains of the Coldbrook Group can be combined into six larger units, each displaying a similar pattern $(A, B, C, D, E, F)$. Similarly, no appreciable difference can be established among the six subdomains of the Central Intrusive Belt. After making all the simplifications possible, the number of areas dism playing comparable patterns have been reduced from 45 to 15 and the characteristic peaks for these are shown in Figure 6.

\section{Some special patterns}

Despite the seemingly insurmountable problems in sorting and correlating lineament patterns from domain to domain and the possibility of many alternate interpretations, there are a few patterns 

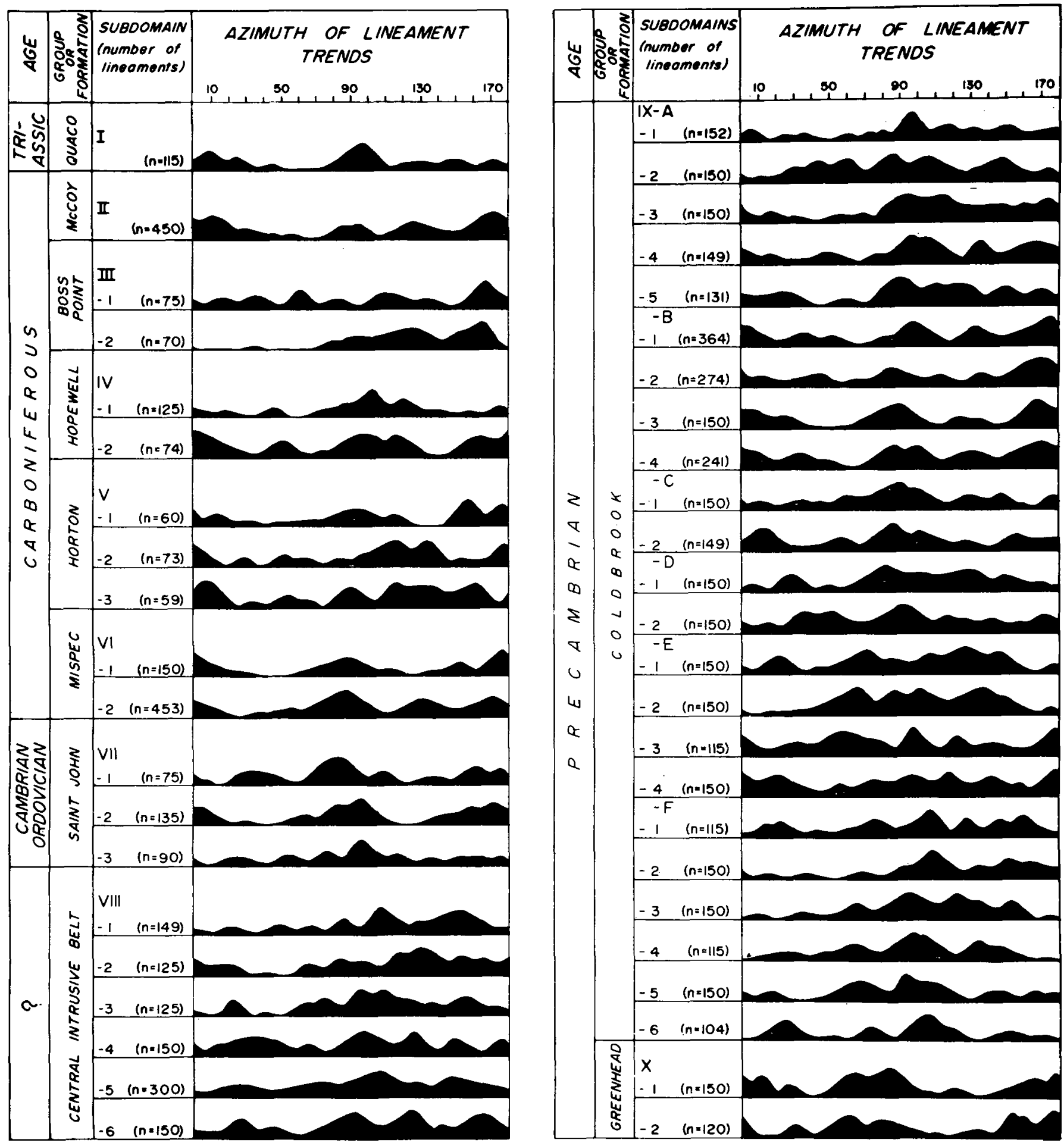

FIG. 3 Distribution of photolineaments in 45 subdomains. Intensity of trends is relative (not to scale). 


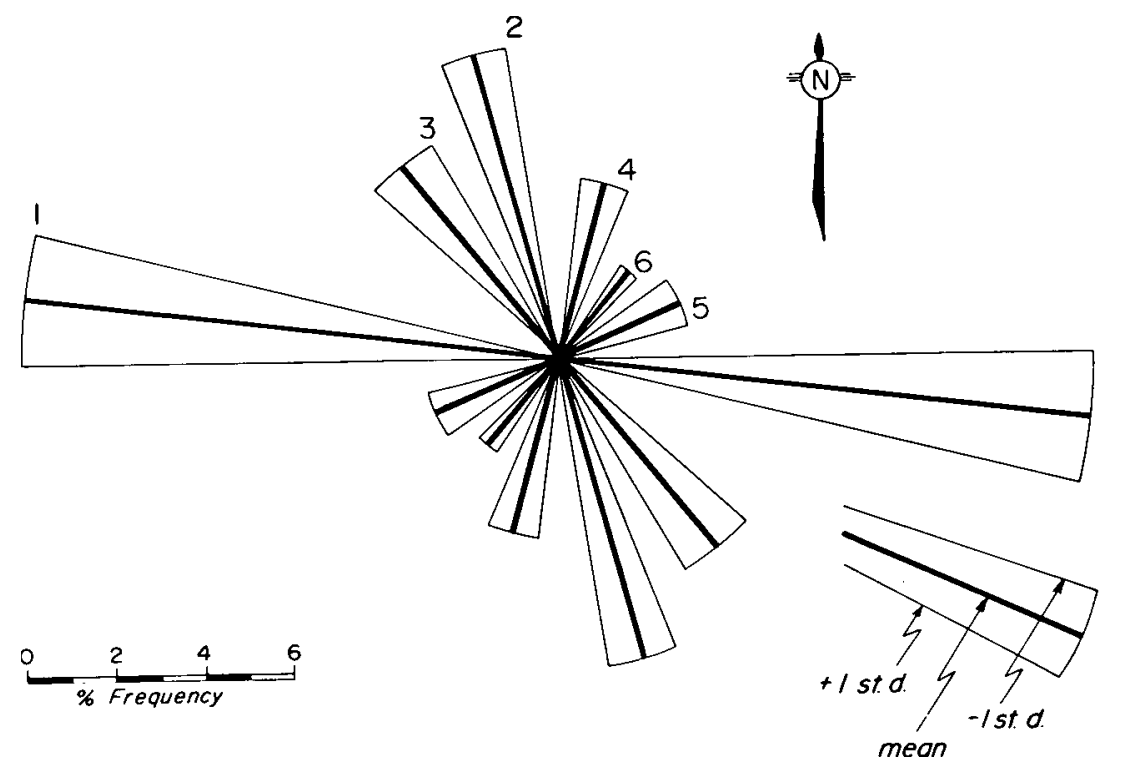

FIG. 4 The distribution of all lineaments of the Caledonia area. The six lineament trends have been established through a statistical partitioning technique (Sinclair, 1974). which are consistent enough not to be open to alternate hypotheses. These are discussed now:

(1) The youngest rocks of the Triassic Quaco Formation carry a single orthogonal system of lineaments in approximately north-south (Q1) and eastwest (Q2) directions (Fig. 6). Both lineaments recur in the Westphalian McCoy Formation but from then on, as one proceeds toward older rocks, their presence is more open to argument. It is probable that $\mathrm{Q} 2$ is represented right through the geological column as suggested on Figure 6 .

(2) Rocks of the next in age McCoy Head Formation carry the two Quaco lineaments plus two new ones at about $130^{\circ}$ (M1) and $170^{\circ}$ (M2). M2 is present in almost all domains while $\mathrm{Ml}$ is present only in the Horton, Central Intrusive Belt, Mispec and some of the Coldbrook subdomains.

(3) The rest of the Carboniferous rocks (Boss Point, Hopewell, Horton) do not have such well-defined peaks as do the earlier formations. The Boss Point Formation has one well-defined peak at $170^{\circ}$, apparently the M2, and a broad pattern at $105^{\circ}-130^{\circ}$ (BI). The most interesting feature of the Hopewell pattern is the weak but nonetheless well-defined peak at $45^{\circ}$ (HWI) which is present in both subdomains (Fig. 3) and in the Saint John and some of the Coldbrook domains. The Horton Group shows a very diffuse pattern when the three subdomains are examined (Fig. 3). On combining all three subdomains (Fig. 6) there is some indication of trends at north-south (M2) and a broad east-west $\left(85^{\circ}-135^{\circ}\right)$ trend which may carry as many as a maximum of three and a minimum of two $(22$, Ml) lineaments; in addition there is a well-defined peak at $160^{\circ}$ (HRl).

(4) The Mispec Formation, thought to be the oldest of the Carboniferous rocks, shows strong similarity to the McCoy patter. However, only three strong peaks are present which probably correspond to $\mathrm{Q} 2$, $\mathrm{Ml}$ and $\mathrm{M} 2$. Also note that $\mathrm{Ml}$ changes orientation from $135^{\circ}$ in the Balls Lake Formation to $150^{\circ}$ in the West Beach Formation (Fig. 5).
Interpretation beyond the Carboniferous domains becomes even more difficult. The volcanic rocks of the Precambrian Coldbrook Group show a very diffuse pattern. Some of the highlights are as follows:

(5) The Cambrian-Ordovician Saint John Group has two strong but rather wide trends at $70^{\circ}-110^{\circ}$ and $150^{\circ}-180^{\circ}$. Each trend may hide, however, two peaks (S2, Q2 and HRI, M2 respectively). Besides these, there are weaker but very persistent peaks at about $30^{\circ}$ (SI) and $55^{\circ}$ (HWI).

(6) The Central Intrusive Belt, although variable from subdomain to subdomain, shows clearly defined trends at $30^{\circ}$ (SI) and at about $155^{\circ}$ (HRI) and a broad central trend between $70^{\circ}$ and $130^{\circ}$ which may hide as many as three individual trends at $70^{\circ}, 100^{\circ}$ and $130^{\circ}$ (S2, $\left.22, \mathrm{Ml}\right)$.

(7) The Coldbrook volcanics underlie over onehalf of the study-area. Lineament distributions have been evaluated in 23 subdomains. On further grouping of similar patterns it was possible to reduce the number of subdomains to 6 groupings $(A, B, C, D, E, F)$.

Subdomain $\mathrm{A}$ has the stronger $\mathrm{Q} 2$ peak, a smaller but clearly defined peak at M2 and minor peaks at SI, HWI, MI and HRI.

Subdomain B (close to Saint John) is remarkable in showing strong resemblance to the McCoy and Mispec pattern of the second quadrant (i.e. trends Q2! M1, M2 and there is a suggestion of $Q 1$ as well). The only difference is the presence of Sl in the coldbrook.

Subdomain $C$ shows the strong imprint of $Q 1, Q 2$ and M2 trends with minor peaks at HWl, MI and HRl.

Subdomain D is very similar to A. Minor differences lie in having a trace of BI and a slightly higher peak at $\mathrm{SI}$.

Although subdomain $\mathrm{E}$ has the stronger $\mathrm{Q} 1, \mathrm{Q} 2$ 


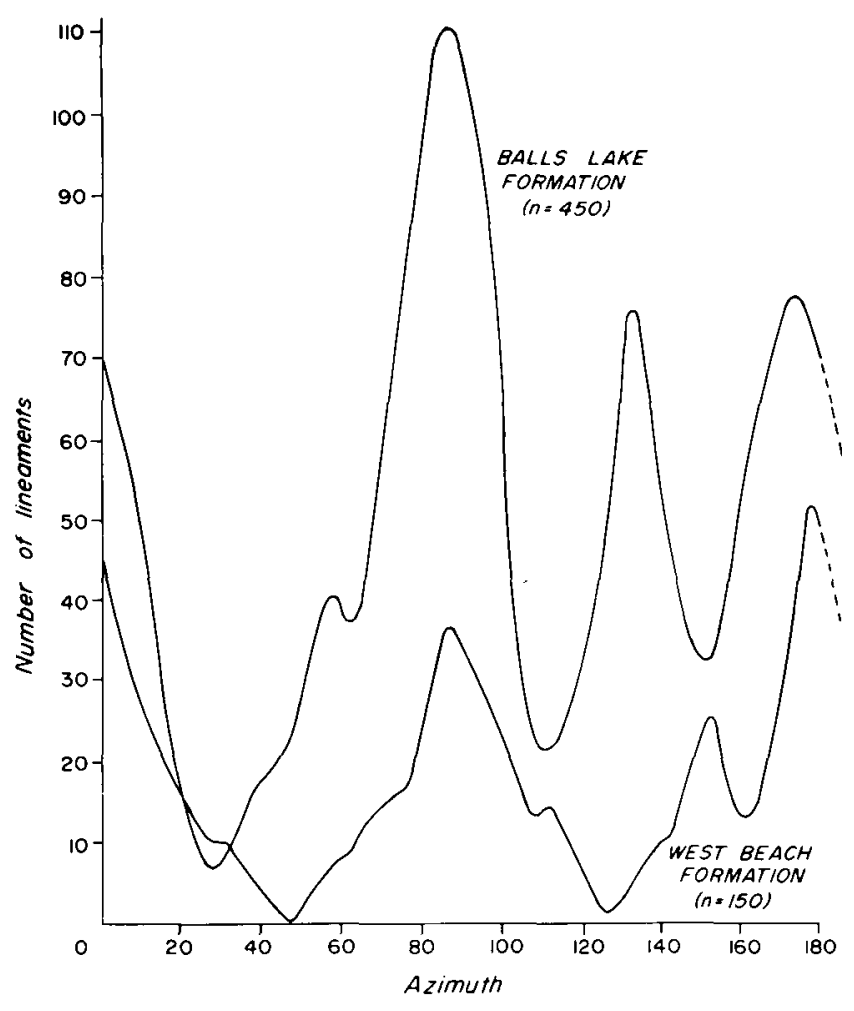

FIG. 5 The distribution of lineaments in the two formations of the Mispec Group. The distribution data have been smoothed.

FIG. 6 Summary of lineament data. Intensity of trends is relative (not to scale).

and M2 peaks it differs from the other subdomains in the Coldbrook in that it has a strong 52 peak.

Subdomain $F$ has the strong $Q 2$ peak with smaller, but clearly defined Q1, S2 and HRl peaks. There is no suggestion of any of the other peaks.

(8) The Greenhead Group shows two strong, but wide belts, one at $50^{\circ}-90^{\circ}$ and the other at $145^{\circ}$ $180^{\circ}$. At least two and possibly three peaks are indicated within each trend.

\section{DISCUSSION}

The common interpretation of airphoto lineaments is that they are the surface expression of fractures in bedrock. In areas of high relative relief, a fracture must be very steep to produce a linear surface feature. In structurally simple areas (e.g. flat-lying sediments) photolineaments are usually produced by vertical-joints (e.g. Babcock, 1974). Alternatively they may be surface features caused by steep faults, bedding and cleavage. Line-

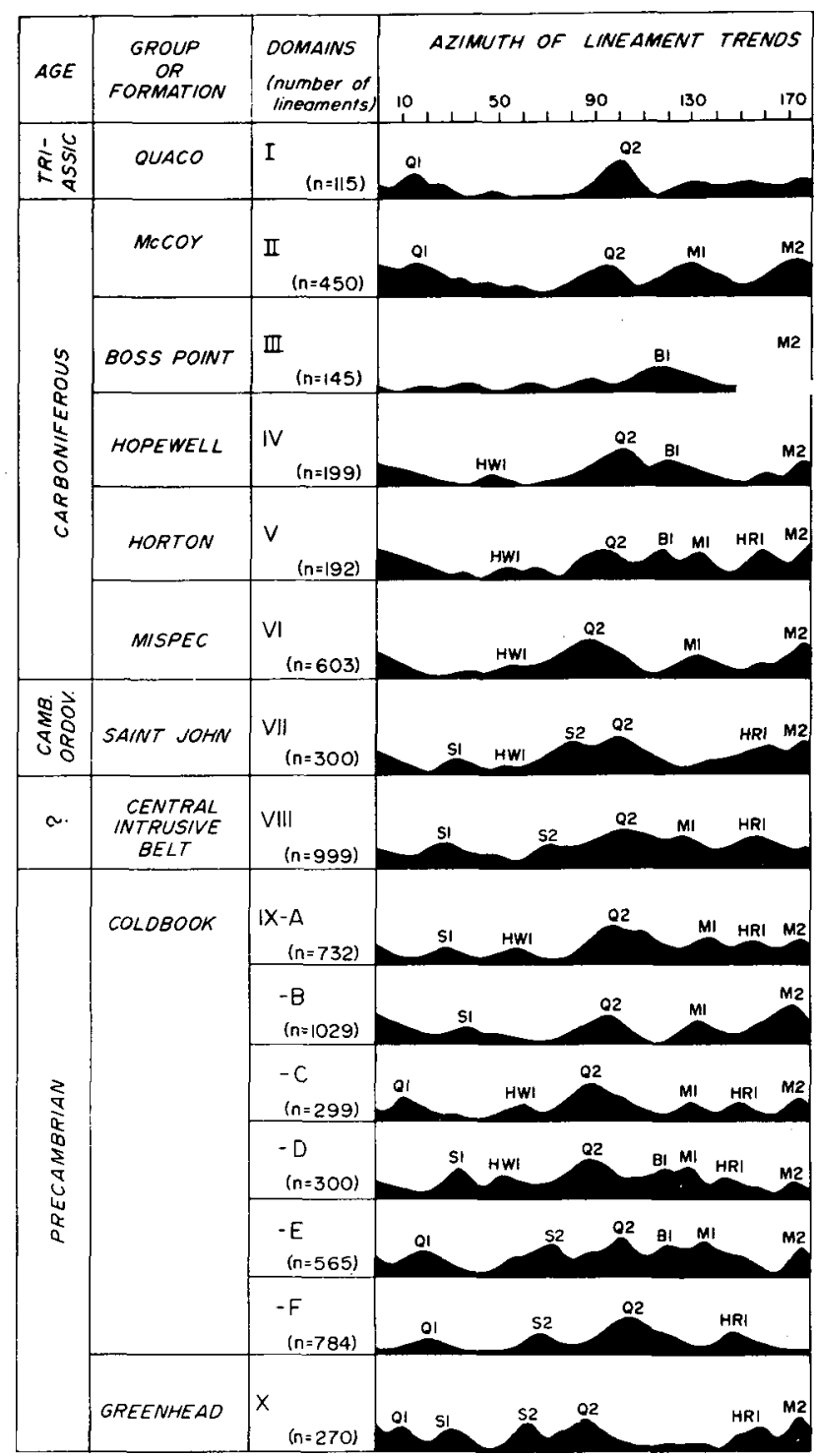

aments of the Caledonia Highlands could be the product of any of these. Using available data from existing literature and from ground checks by the senior author, an attempt has been made to relate airphoto observations to geological features on the ground. This can be found in Naing (1976). In view of the complexity of geological conditions on the ground and the scarcity of data on directional properties of any kind, a dynamic interpeetation of lineament patterns, however, is not possible. The most one can do is to compare lineaments with major faults of the area by using the photogeology maps of Naing (1976) and other maps, particularly in Ruitenberg et al 1975). Fault orientations taken from these are plotted in a frequency distribution form on Figure 7.

Although the difference between the two distribution curves is quite large, both indicate that most major faults are northeasterly. Interestingly, few lineaments occur in this direction (Fig. 6). It is suggested therefore that airphoto lineaments are produced by joints rather than faults. Future 


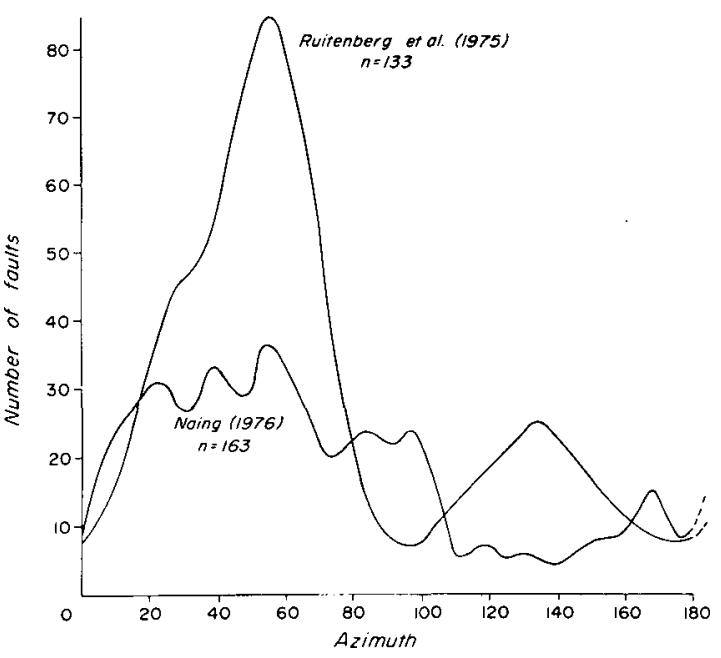

investigations will therefore be directed to evaluate joint patterns in the Caledonian Highlands. Hopefully as more data become available, a dynamic analysis of lineament patterns will be possible and this in turn should aid in the interpretation of the complex structure of the Caledonian Highlands of New Brunswick.

\section{ACKNOWLEDGEMENTS}

Financial assistance for this project has been provided by Canadian International Development Agency and the Government of the Union of Burma. The writers acknowledge the assistance of Professors of the University of New Brunswick, particularly that of Profs. Burke, Rast and Dereny. Ms. D. Quigg prepared the diagrams and typed the manuscript.

\section{REFERENCES}

BABCOCK, E.A. 1974. Photolineaments and regional joints: Lineament density and terrain parameters, South-Central Alberta. Bull. of Can. Geol. vol. 22 , pp. 89-105.

BROWN, R.L. and HELMSTAEDT, H. 1970. Deformation history in part of the Lubec-Belleisle zone of southern New Brunswick. Can. Journ. Earth Sc. vol. 7, pp. 748-767.

GARNET, J.A. and BROWN, R.L. 1973. Fabric variation in the Lubec-Belleisle zone of southern New Brunswick. Canadian Journ. Earth Sc., vol. 10, pp. 1591-1599.

GREINER, H. 1974. Geomorphotology of the Fundy National Park, New Brunswick. Maritime Sediments vol. 10, pp. 36-45.

GUPTA, V.L. 1975. An interpretation of aeromagnetic and gravity data of Caledonia area in southern New Brunswick. Unpublished Ph.D. thesis, University of New Brunswick, Fredericton, New Brunswick, Canada.

HOWIE, R.D. and CUMMING, L.M. 1963. Basement features of the Canadian Appalachians. Geol. Surv. Canada. Bull. 89.
FIG. 7 Distribution of major fault trends in the Caledonia area based on available geological maps.

NAING, W. 1976. Photogeology of the Caledonia area of southern New Brunswick. Unpublished Ph.D. thesis, University of New Brunswick, Fredericton, New Brunswick, Canada.

POTTER, R.R. 1966. Metallogenic studies in New Brunswick. In Geological Investigations in New Brunswick (J.C. Smith, Ed.). Mines Branch, Department of Lands and Mines, New Brunswick, pp. 20-25.

RAST, N. and GRANT, R.H. 1973. Transatlantic correlation of the Variscan-Appalachian Orogeny. Am. Journ. Sc. vol. 273, pp. 572-579.

RUITENBERG, A.A., VENUGOPAL, D.V., and GILES, P.S. 1973. "Fundy Cataclastic Zone", New Brunswick: evidence for post-Acadian penetrative deformation. Geol. Soc. of America Bull., Vol. 84, pp. 3029-3044.

RUITENBERG, A.A., GILES,.P.S., VENUGOPAL, D.V. and MCCUTCHEON, S.R. 1974. Late Precambrian rocks in the Caledonia Highlands of southeastern New Brunswick. Maritime Sediments, Vol. 9, pp. 83-87.

RUITENBERG, A.A., GILES, P.S., VENUGOPAL, D.V., BUTTIMER, S.M., MCCUTCHEON, S.R., and CHANDRA, J. 19.75. Geological Maps NTS21 H: 4,5E and $W, 6 E$ and $W, 10 W, 11 E$ and $W, 12 E, 14 E, 15 E$ and $W ; 21 G: 1 E$ and $W, 2 E, 3 E$ and $W$, Caledonia area. Mineral Resources Branch, New Brunswick Department of Natural Resources and Canada Department of Regional Economic Expansion.

SINCLAIR, A.J. 1974. Selection of threshold values in geochemical data using probability graphs. Journal of Geochemical Exploration, Vol. 3, pp. 129-149.

TEJIRIAN, H.G. 1974. Trend analysis of aeromagnetic data in the Caledonia area of southern New Brunswick. Unpublished M.Sc. thesis, University of New Brunswick, Fredericton, New Brunswick, Canada. 